\title{
BMJ Open Evaluation of early medication persistence with omidenepag isopropyl, a topical selective prostaglandin EP2 agonist, in patients with glaucoma: a retrospective two-institute study
}

\author{
Shunsuke Nakakura (D) ,'Akiyasu Kanamori, ${ }^{2,3}$ Yasuko Fukuma, ${ }^{1}$ \\ Seita Wakabayashi, ${ }^{3}$ Yuki Nagata, ${ }^{1}$ Miku Adachi ${ }^{1}$
}

To cite: Nakakura S, Kanamori A, Fukuma $Y$, et al. Evaluation of early medication persistence with omidenepag isopropyl, a topical selective prostaglandin EP2 agonist, in patients with glaucoma: a retrospective two-institute study. BMJ Open 2021;11:e040301. doi:10.1136/ bmjopen-2020-040301

- Prepublication history for this paper is available online. To view these files, please visit the journal online (http://dx.doi. org/10.1136/bmjopen-2020040301).

Received 10 May 2020 Revised 08 January 2021 Accepted 20 January 2021

Check for updates

(c) Author(s) (or their employer(s)) 2021. Re-use permitted under CC BY-NC. No commercial re-use. See rights and permissions. Published by BMJ.

${ }^{1}$ Ophthalmology, Saneikai Tsukazaki Hospital, Himeji, Japan

${ }^{2}$ Ophthalmology, Division of Surgery, Kobe University, Kobe, Japan

${ }^{3}$ Kanamori Eye Clinic, Akashi, Japan

Correspondence to Dr Shunsuke Nakakura; shunsukenakakura@yahoo.co.jp

\section{ABSTRACT}

Objectives We evaluated early medication persistence with new topical antiglaucoma eyedrops, omidenepag isopropyl $0.002 \%$ (a selective prostaglandin EP2 agonist).

Design and setting Retrospective two-institute study in Himeji and Akashi in Japan.

Participants We analysed patients with glaucoma who were prescribed topical omidenepag isopropyl from November 2018 to December 2019. From the last outpatient visit of patients until February 2020, 235 patients were prescribed a new solution of omidenepag isopropyl (129 patients in the initial monotherapy group, 85 in the switching group (switched from another topical antiglaucoma eyedrops), 19 added to another topical antiglaucoma eyedrops group, and 2 were lost to followup)). Additionally, we recruited 98 patients (3 were lost to follow-up) who received initial latanoprost $0.005 \%$ monotherapy during the same period as a control group. Outcomes Medication persistence failure was defined as drug discontinuation due to any adverse effects or change of therapy. Kaplan-Meier survival analysis was performed with a Cox regression analysis.

Results Among 233 patients, 48 (20\%) showed failure of treatment; the median persistence time of all patients was 165 days, and the median time until discontinuation of omidenepag isopropyl was 45 days. The total persistence rates were $85 \%, 80 \%$ and $70 \%$ at 3,6 and 12 months, respectively. Risk factors for failure were male gender (HR: 1.45, $\mathrm{p}=0.023)$ and monotherapy/switching (HR: $1.715, p=0.002)$. Comparison between latanoprost and omidenepag isopropyl monotherapy, only male gender (HR: 1.43, $p=0.016$ ) was a significant risk factor. Failures associated with omidenepag isopropyl were due to insufficient intraocular pressure-lowering efficiency $(n=26$, observed during all the period), followed by conjunctival hyperaemia $(n=10)$ and visual acuity disturbance $(n=5)$ in patients who were observed until 3 months.

Conclusion Medication persistence with omidenepag isopropyl is mostly positive; however, clinicians should also be cautious of early failure.
Strengths and limitations of this study

- This study is the first to evaluate the early persistence with omidenepag isopropyl, which is a new topical antiglaucoma drug.

- We collected the data from two institutes of all the patients who were administered omidenepag isopropyl during the first year of its market launch.

- We also compared the persistence rate of omidenepag isopropyl monotherapy with latanoprost monotherapy.

- Our study has few limitations as it is retrospective in nature and demonstrates short-term results.

- Selection bias might reflect the differences in patient backgrounds between omidenepag isopropyl and latanoprost monotherapies.

\section{INTRODUCTION}

Glaucoma is one of the major leading causes of blindness worldwide. Researchers have already identified some glaucoma-associated risk factors such as high intraocular pressure (IOP), thinner cornea, ethnicity and age. ${ }^{1-3}$ Currently, reduction of IOP is the only available evidence-based treatment that reduces visual field deterioration in glaucoma. ${ }^{45}$ IOPlowering medicated eyedrops are commonly used as the first-line treatment for glaucoma. However, patients' adherence or compliance plays a crucial role in treatment persistence. A previous systematic review showed that the persistence with newly prescribed topical glaucoma medications was around $60 \%$ in the first year. ${ }^{6}$ Among various antiglaucoma eyedrops, better persistence has been observed with prostaglandin F2 $\alpha$ (latanoprost $0.005 \%$ ) than with other prostaglandin analogues (bimatoprost and travoprost), $\beta$-blockers, alpha agonists and carboxyl anhydrase inhibitors. ${ }^{7-11}$ Recently, omidenepag 
isopropyl, a selective prostaglandin EP2 agonist with a non-prostaglandin structure, has been developed. Omidenepag isopropyl increases the outflow of aqueous humour via both the uveoscleral and trabecular outflow pathways, which results in potent and stable reduction in IOP. $^{12}$ Studies in humans have confirmed that the IOPlowering efficacy of omidenepag isopropy ${ }^{12-14}$ is not inferior to that of latanoprost during the first month. ${ }^{14}$ In November 2018, an ophthalmic solution of omidenepag isopropyl 0.002\% (EYBELIS; Santen Pharmaceutical Co, Ltd, Osaka, Japan) became available in Japan for the treatment of glaucoma and ocular hypertension. Unlike the case with conventional prostaglandin $\mathrm{F} 2 \alpha$ analogues, periorbital changes that occur as an adverse effect (known as 'prostaglandin-associated periorbital syndrome' $)^{15}$ were observed to improve in patients who were switched to omidenepag isopropyl. ${ }^{16}$ The primary objective of this study was to investigate early medication persistence with topical omidenepag isopropyl and the causes of its discontinuance in real-world settings. The secondary objective was to compare medication persistence with initial omidenepag isopropyl and that with initial latanoprost $0.005 \%$ monotherapy, which is commonly used as the first-line treatment for glaucoma, thereby speculating whether omidenepag isopropyl can also be used as the first-line treatment for glaucoma.

\section{METHODS}

\section{Study subjects}

The Institutional Review Board (IRB) waived the requirement of informed consent for this study on the basis of ethical guidelines for medical and health research involving human subjects established by the Japanese Ministry of Education, Culture, Sports, Science, and Technology and by the Ministry of Health, Labour, and Welfare. The waiver was granted because the study was a retrospective chart review, not an interventional study, and because it was difficult to obtain consent from patients who had been treated several years before the study. At the request of the IRB, however, we published an outline of the study, which is available for public viewing at both the offices. This public posting also gave patients the opportunity to decline participation, although none of the patients did so. Personal identifiers were removed from all records before data analysis.

First, all patients who were prescribed omidenepag isopropyl from November 2018 (when this drug was launched in the market) to December 2019 were picked up using electronic medical records. The patients' visits to our institute concluded in February 2020 because nearly all the patients returned within 2 months after the first prescription to check the adverse effects or IOPlowering efficiency of omidenepag isopropyl. All patients were scheduled for 1 to 2 months follow-up, and clinicians performed full ophthalmic examinations at each visit. In general, the omidenepag isopropyl was not prescribed to patients with intraocular lens implantation or those who previously underwent glaucoma surgery in advance because it can induce cystoid macula oedema in patients with pseudophakia. ${ }^{17}$ Finally, patients treated with omidenepag isopropyl could be divided into three groups: monotherapy group, switching group (switching from another drug to omidenepag isopropyl) and added group (omidenepag isopropyl was added to another drug).

Additionally, we enrolled patients who were treated with latanoprost $0.005 \%$ (Xalatan, Pfizer Inc, New York, New York) as the initial monotherapy to serve as a control group to compare against those receiving omidenepag isopropyl as the initial monotherapy. Patients treated with latanoprost monotherapy were enrolled in both institutes during the same period as that of omidenepag isopropyl using the electronic medical records.

Exclusion criteria included patients (1) who had missed the first clinical examination after the first prescription of latanoprost or omidenepag isopropyl, (2) who previously used fixed combination treatment with latanoprost or generic latanoprost, (3) who were lost to follow-up for more than 3 months and (4) who had previously used latanoprost or omidenepag isopropyl.

Medication persistence failure was defined as the percentage persistence until discontinuation or change of therapy, ${ }^{6}$ that is, discontinuation of omidenepag isopropyl or latanoprost due to any adverse effects, switching to another drug due to insufficient IOP-lowering efficacy or addition of any other drug due to insufficient IOPlowering efficacy. All causes of persistence failure with both glaucoma medications were investigated by all authors. We checked the electronic records of all the visits of all the patients for whom omidenepag isopropyl was prescribed. Therefore, the causes and times of therapy discontinuation were thoroughly investigated.

\section{Statistical analysis}

Statistical analyses were performed using JMP software V.10.0.0 (SAS Institute Inc, Cary, North Carolina) and Statcel 3 (OMS Publishing Ltd, Tokyo, Japan). We used Kaplan-Meier survival curves to determine the persistence rate for three different treatment strategies using omidenepag isopropyl as well as latanoprost monotherapy as the control group. The association between survival duration and the predictor variables (1) age, (2) sex, (3) glaucoma type (primary open-angle glaucoma, normal tension glaucoma or others) and (4) type of therapy (monotherapy, switching or added) was investigated with the multivariable Cox proportional hazards model among groups of patients taking omidenepag isopropyl. We also performed multivariable Cox proportional hazards model analysis to compare patients receiving omidenepag isopropyl monotherapy with those receiving latanoprost monotherapy.

Mann-Whitney $U$ test and $\chi^{2}$ test were used to compare patient characteristics between omidenepag isopropyl and latanoprost groups. A p value of less than 0.05 was considered statistically significant. 


\section{Patients and public involvement}

No public was involved in this study. We were unable to disseminate the results of the research directly to the study participants.

\section{RESULTS}

During the study period, 235 patients were prescribed omidenepag isopropyl and 98 patients were prescribed initial latanoprost solution. We analysed a final cohort of 233 patients receiving omidenepag isopropyl and 95 patients receiving latanoprost. Two patients missed the first clinical examination after the first prescription of omidenepag isopropyl. One patient in the latanoprost group had been using generic latanoprost, and two patients missed the first clinical examination after the first prescription of latanoprost. Among the omidenepag isopropyl groups, 129 patients received monotherapy, 85 switched from another glaucoma eyedrops to omidenepag isopropyl and 19 belonged to the group in which omidenepag isopropyl was added to other glaucoma eyedrops. In 85 patients who switched from another drug to omidenepag isopropyl, the preceding eyedrops were prostaglandin analogues in 42 patients, $\beta$-blockers in 14 , a fixed combination of $\beta$-blockers and carboxyl anhydrase inhibitors in 10 , alpha agonists in 9 , a fixed combination of prostaglandin analogues and $\beta$-blockers in 5 , ripasudil in 4 and a fixed combination of $\beta$-blockers/carboxyl anhydrase inhibitors and alpha agonists in 1 .

Table 1 shows patient demographics and persistence data. The median persistence time of all patients was 165 days (quantile: 70, 273 days), and 48 patients (20\%) met the failure criteria. The median length of time until failure was 28 days in the omidenepag isopropyl monotherapy group; 99 days in the omidenepag isopropyl switching group; and 38 days in the omidenepag isopropyl added group. The persistence rates were up to $93 \%, 85 \%, 80 \%, 75 \%$ and $70 \%$ at $1,3,6,9$ and 12 months, respectively (figure 1A). The persistence rates of omidenepag isopropyl monotherapy group were up to $90 \%, 87 \%, 80 \%, 78 \%$ and $78 \%$ at $1,3,6,9$ and 12 months, respectively (figure 1B). The persistence rates of omidenepag isopropyl switching group were up to $97 \%$, $89 \%, 81 \%, 76 \%$ and $66 \%$ at $1,3,6,9$ and 12 months, respectively (figure 1C). The persistence rates of omidenepag isopropyl added group were up to $94 \%, 73 \%, 73 \%$, $58 \%$ and $58 \%$ at $1,3,6,9$ and 12 months, respectively (figure 1D). Table 2 shows the results of the Cox proportional hazards model. Male gender (HR: 1.45; 95\% CI:

Table 1 Patient demographics

\begin{tabular}{|c|c|c|c|c|c|}
\hline \multirow[b]{2}{*}{ Attribute } & \multicolumn{4}{|c|}{ Omidenepag isopropyl $0.002 \%$} & \multirow{2}{*}{$\begin{array}{l}\text { Latanoprost } \\
0.005 \% \\
\begin{array}{l}\text { Monotherapy } \\
\text { group }\end{array}\end{array}$} \\
\hline & $\begin{array}{l}\text { Monotherapy } \\
\text { group }\end{array}$ & $\begin{array}{l}\text { Switching } \\
\text { group }\end{array}$ & Added group & All & \\
\hline Number (n) & 129 & 85 & 19 & 233 & 95 \\
\hline Treated eye, both (n) & 79 & 49 & 6 & 134 & 76 \\
\hline Median age (quantile) & $56(48.5,62)$ & $57(49,66)$ & $63(55,67)$ & $57(49,64)$ & $66(56,74)$ \\
\hline Sex (female), \% & $74(57)$ & $61(72)$ & $12(63)$ & $147(62)$ & $54(57)$ \\
\hline \multicolumn{6}{|l|}{ Glaucoma type } \\
\hline Primary open-angle glaucoma (n, \%) & $36(28)$ & $50(59)$ & $10(53)$ & $96(41)$ & $57(60)$ \\
\hline Normal tension glaucoma $(\mathrm{n}, \%)$ & $89(69)$ & $32(38)$ & $6(31)$ & $127(55)$ & $29(31)$ \\
\hline Others (n, \%) & $4(3)$ & $3(3)$ & $3(16)$ & $10(4)$ & $9(9)$ \\
\hline Median survival time (quantile) & $135(60.5,246.5)$ & $231(90,317)$ & $136(42,252)$ & $165(70,273)$ & $188(106,277)$ \\
\hline $\begin{array}{l}\text { Total number of patients who } \\
\text { discontinued the drug (n, \%) }\end{array}$ & $23(18)$ & $19(22)$ & $6(31)$ & $48(20)$ & $14(15)$ \\
\hline $\begin{array}{l}\text { Median time until discontinuation } \\
\text { (quantile) }\end{array}$ & $28(17,118)$ & $99(47,184)$ & $38.5(29,96)$ & $45.5(28,136.7)$ & $102.5(42,113.7)$ \\
\hline $\begin{array}{l}\text { Causes of discontinuation (including } \\
\text { multiple answers) total ( } \mathrm{n} \text { ) }\end{array}$ & 27 & 19 & 6 & 52 & 14 \\
\hline Inadequate IOP lowing efficiency (n, \%) & $13(48)$ & $11(58)$ & $2(33)$ & $26(50)$ & $14(100)$ \\
\hline Visual acuity disturbance (n, \%) & $3(11)$ & $2(10)$ & - & $5(10)$ & - \\
\hline Conjunctival hyperaemia $(\mathrm{n}, \%)$ & $6(22)$ & $2(10)$ & $2(33)$ & $10(19)$ & - \\
\hline Allergy (n, \%) & - & $1(5)$ & $1(17)$ & $2(4)$ & - \\
\hline $\begin{array}{l}\text { Others (dry eye, ocular pain, glare, etc) (n, } \\
\%)\end{array}$ & $5(19)$ & $3(16)$ & $1(17)$ & $9(17)$ & - \\
\hline
\end{tabular}

IOP, intraocular pressure. 

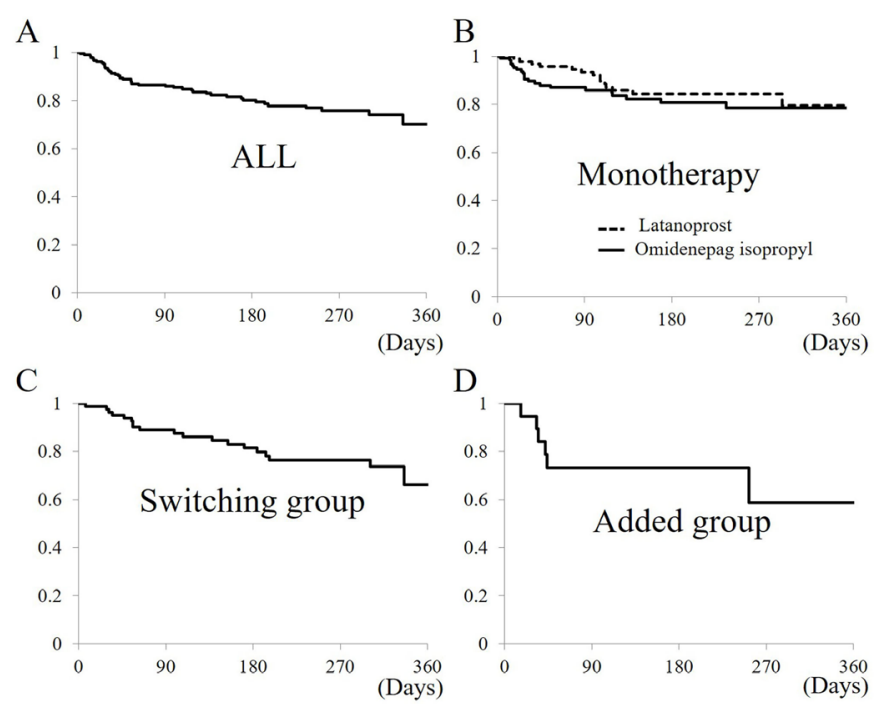

Figure 1 Kaplan-Meier survival analysis. (A) All patients treated with omidenepag isopropyl. The cumulative persistence rates were $85 \%, 80 \%$ and $70 \%$ at 3, 6 and 12 months, respectively. (B) We used Kaplan-Meier survival analysis to compare cumulative persistence rates between omidenepag isopropyl and latanoprost monotherapy groups. The cumulative persistence rates of omidenepag isopropyl and latanoprost were $87 \%$ and $93 \%$, respectively, at 3 months, $80 \%$ and $84 \%$, respectively, at 6 months and $78 \%$ and $79 \%$, respectively, at 12 months. (C) Patients who switched to omidenepag isopropyl. The cumulative persistence rates were $89 \%, 81 \%$ and $66 \%$ at 3,6 and 12 months, respectively. (D) Patients with omidenepag isopropyl added to other glaucoma eyedrops. The cumulative persistence rates were $73 \%, 73 \%$ and $58 \%$ at 3, 6 and 12 months, respectively.

Table 2 Multivariable Cox proportional hazards ratios for risk factors in failure to continue omidenepag isopropyl treatment

\begin{tabular}{|c|c|c|c|}
\hline Attribute & HR & $P$ value & $95 \% \mathrm{Cl}$ \\
\hline Age, per 1 year & 1.00 & 0.483 & 0.991 to 1.019 \\
\hline Sex (male) & 1.450 & 0.0230 & 1.053 to 1.986 \\
\hline \multicolumn{4}{|l|}{ Glaucoma type } \\
\hline POAG/NTG & 0.971 & 0.868 & 0.691 to 1.357 \\
\hline POAG/others & 0.812 & 0.671 & 0.350 to 2.366 \\
\hline NTG/others & 0.835 & 0.715 & 0.356 to 2.450 \\
\hline \multicolumn{4}{|l|}{ Treatment type } \\
\hline Monotherapy/switching & 1.715 & 0.002 & 1.214 to 2.442 \\
\hline Monotherapy/added & 1.341 & 0.345 & 0.740 to 2.619 \\
\hline Switching/added & 0.782 & 0.445 & 0.436 to 1.510 \\
\hline
\end{tabular}

NTG indicates normal tension glaucoma; POAG, primary open-angle glaucoma.

$P$ values $<0.05$ were considered statistically significant

$\mathrm{HR}$; hazard ratio

NTG, normal tension glaucoma; POAG, primary open-angle glaucoma.
Table 3 Multivariable Cox proportional hazards ratios for risk factors in failure to continue omidenepag isopropyl monotherapy and latanoprost monotherapy

\begin{tabular}{|c|c|c|c|}
\hline Attribute & HR & $P$ value & $95 \% \mathrm{Cl}$ \\
\hline Age, per 1 year & 1.004 & 0.504 & 0.991 to 1.017 \\
\hline Sex (male) & 1.439 & 0.016 & 1.067 to 1.933 \\
\hline \multicolumn{4}{|l|}{ Glaucoma type } \\
\hline POAG/NTG & 0.885 & 0.490 & 0.624 to 1.249 \\
\hline POAG/others & 1.139 & 0.712 & 0.592 to 2.473 \\
\hline NTG/others & 1.287 & 0.493 & 0.643 to 2.872 \\
\hline \multicolumn{4}{|l|}{ Glaucoma medication } \\
\hline $\begin{array}{l}\text { Omidenepag isopropyl/ } \\
\text { latanoprost }\end{array}$ & 1.316 & 0.129 & 0.922 to 1.890 \\
\hline
\end{tabular}

NTG indicates normal tension glaucoma; POAG, primary openangle glaucoma.

$P$ values $<0.05$ were considered statistically significant. HR, hazard ratio; NTG, normal tension glaucoma; POAG, primary open-angle glaucoma.

1.05 to $1.98 ; \mathrm{p}=0.023$ ) and monotherapy, as opposed to switching therapy (HR: $1.71 ; 95 \%$ CI: 1.21 to 2.44 ; $\mathrm{p}=0.002$ ), were the significant risk factors for discontinuation of omidenepag isopropyl treatment.

\section{Comparison of monotherapy with omidenepag isopropyl and latanoprost $\mathbf{0 . 0 0 5 \%}$}

In the latanoprost monotherapy group, the median persistence time of all patients was 188 days (quantile; $106,277)$ and 14 patients $(15 \%)$ showed persistence failure. The persistence rates of latanoprost monotherapy group were up to $97 \%, 93 \%, 84 \%, 84 \%$ and $79 \%$ at 1, 3, 6, 9 and 12 months, respectively (figure 1B). Regarding patient backgrounds, no significant difference was observed in sex $(p=0.937)$, the number of failures $(p=0.537)$ or median length of time until discontinuation (day; $\mathrm{p}=0.07$ ) between omidenepag isopropyl and latanoprost monotherapy groups. However, we found significant differences in age $(p<0.001)$, disease $(p<0.001)$, median survival time (days) $(\mathrm{p}<0.001)$ and causes of failure of therapy $(p=0.011$ ) between the groups.

Table 3 shows the results of Cox proportional hazards analysis. Male gender (HR: 1.43; 95\% CI: 1.06 to 1.93; $\mathrm{p}=0.016$ ) was the only significant risk factor for discontinuation of omidenepag isopropyl monotherapy and latanoprost monotherapy. The HR between omidenepag isopropyl monotherapy and latanoprost monotherapy was not significant (HR: 1.316; $\mathrm{p}=0.129$ )

\section{Causes of failure of omidenepag isopropyl}

Table 1 and figure 2 show the detailed causes of failure of omidenepag isopropyl. From 48 patients who showed failure of the treatment with omidenepag isopropyl, we obtained 52 reasons for the failure. The most frequent reason was insufficient IOP-lowering efficacy $(n=26,50 \%)$ including surgical introduction $(\mathrm{n}=5)$ and visual field progression $(\mathrm{n}=1)$. The median time until failure was 55.5 


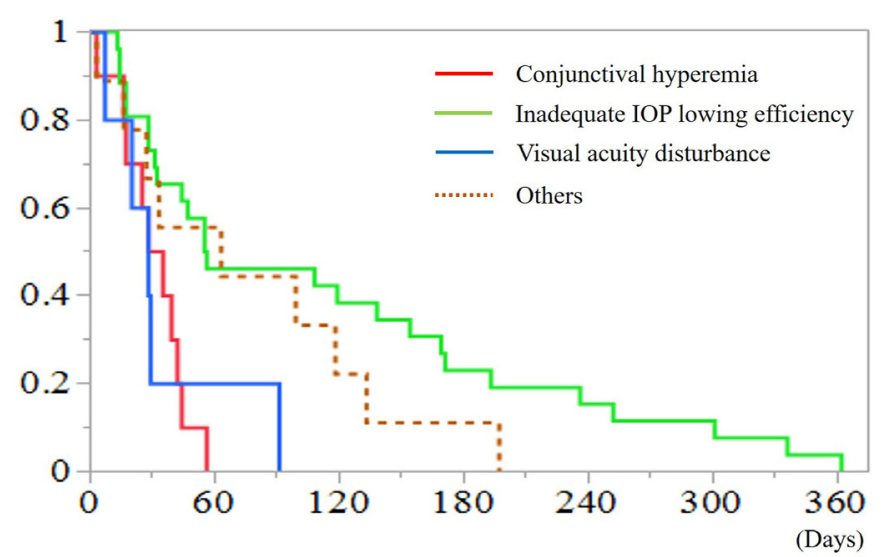

Figure 2 Kaplan-Meier plots: development of each cause of failure over time. Failure due to conjunctival hyperaemia and visual acuity disturbance was often observed until 3 months of administration. Insufficient IOP-lowering efficacy was observed at any particular time during this period. An allergy plot is not shown because allergy was analysed at only two time points. IOP, intraocular pressure.

(range: 13-362) days. Conjunctival hyperaemia occurred in 10 patients, and the median time until failure was 31.5 (range: 3-56) days. Visual acuity disturbance occurred in five patients who complained of blurred vision, and the median time until failure was 28 (range: 7-91) days. Other $(n=9)$ adverse effects included ocular pain $(n=2)$, dry eyes $(n=1)$ and glare $(n=1)$. Their median time until failure was 63 (range: 3-197) days. Allergy was observed in two patients (day 35 and 184, respectively). Figure 2 shows the plots of the number of days until failure and its causes. Visual acuity disturbance and conjunctival hyperaemia were often observed until 3 months.

\section{DISCUSSION}

In this retrospective study, we confirmed that the early persistence with omidenepag isopropyl is favourable and nearly similar to that of latanoprost monotherapy. Male gender and monotherapy, as opposed to switching therapy, were the risk factors for early medical persistent failure. Across 12 studies in a previous review, ${ }^{6}$ a mean of $40 \%$ (range: $14 \%-67 \%$ ) patients remained under the same criteria as that of the current study in the first year. The patients in our study who were administered with omidenepag isopropyl showed $70 \%$ persistence at the first year. In monotherapy persistence, similar persistence under this criteria was observed between omidenepag isopropyl (78\% at first year) and latanoprost (79\% at first year) ( $\mathrm{p}=0.282$ by log-rank tests), which is superior to that reported in previous reports of newly prescribed monotherapy. ${ }^{8918-21}$ The reported persistence with latanoprost in the first year was 23\%, ${ }^{8}$ about $20 \%,{ }^{9}$ about $30 \%,{ }^{18}$ about $35 \%,{ }^{21}$ about $40 \%,{ }^{19} 64 \%{ }^{20}$ (references values of 9 , 18,19 and 21 were calculated by its original figure) under the same persistence criteria of percentage persistence until discontinuation or change of therapy. Previously, diversity in patient backgrounds due to insurance, ${ }^{22}$ income ${ }^{23}{ }^{24}$ race $^{22}$ and hospital accessibility ${ }^{24}$ was associated with persistence. In a similar report of persistence in Japanese patients with glaucoma, Kashiwagi ${ }^{25}$ mentioned that all Japanese citizens are required to possess a health insurance and the insurance should cover at least $70 \%$ of medical expenses. However, the difference in income among the Japanese population is small. Therefore, patients with such background problems may have a less impact on our persistence rate. Another reason of the discrepancy in persistence was the background of age because studies associated with glaucoma persistence were reported from 2002 to $2004 .^{8918-21}$ Therefore, patients cannot easily access information on and understand the disease of glaucoma through an Internet search. A poor glaucoma understanding ${ }^{2325}$ was associated with a lowered persistence rate of glaucoma. At present, the Internet is very popular worldwide, and almost all patients in this study were prescribed by glaucoma specialists. Therefore, education and adherence of patients may be higher in the current study than in patients in previous reports. In this study, the gender was associated with strong evidence of being an important risk factor for failure statistically with the male having 1.45 times higher chance of failure than women; this was a new finding in comparison with previous reports. Another new finding in our study was that monotherapy had a relatively high risk of failure in comparison with switching therapy. This was possibly because most patients receiving omidenepag isopropyl monotherapy were initially prescribed antiglaucoma drugs, whereas patients who switched therapy may have already been accustomed to side effects of antiglaucoma eye drops such as conjunctival hyperaemia, stinging or blurred vision.

Regarding the adverse effects of omidenepag isopropyl, a Phase 3 trial showed that the most frequently reported ocular adverse effects were conjunctival hyperaemia $(18.8 \%)$, followed by macular oedema $(4.7 \%)$ and iritis $(1.2 \%)$ in 85 patients. ${ }^{14}$ After the launch of omidenepag isopropyl in the market, Santen Pharmaceutical Co, Ltd, reported its safety information of 6 months. ${ }^{26}$

In one report, 809 adverse drug reactions of 580 reported patients (approximately 70000 patients were prescribed omidenepag isopropyl). ${ }^{26}$ The commonly reported adverse events were ocular and conjunctival hyperaemia $(\mathrm{n}=187)$, iritis $(\mathrm{n}=86)$, blurred vision $(\mathrm{n}=81)$, ocular pain $(n=43)$, visual acuity disturbance $(n=48)$, macular oedema $(n=23)$ and myopia $(n=16) .{ }^{26}$ The real frequency of occurrence remained unknown, ${ }^{26}$ and the side effects did not directly affect the discontinuation of omidenepag isopropyl. In our study, five patients reported visual acuity disturbance that was resolved after discontinuing omidenepag isopropyl. Figure 2 shows the plots of causes of failure. Conjunctival hyperaemia and visual acuity disturbance have become the apparent causes of early discontinuation. We should pay careful attention to this observation and inform the same to patients before prescribing the eyedrops. 
This study has several limitations. First, this study was retrospective but did not involve a longer follow-up. Especially, regarding the prescription of latanoprost, we have extensive experiences of about 20 years in using this standard drug. Therefore, we may unconsciously avoid the patients who are at a risk for dropping out of the latanoprost therapy. Conversely, we avoided patients with pseudophakia while prescribing omidenepag isopropyl. This selection bias might reflect the differences in patient backgrounds between omidenepag isopropyl and latanoprost monotherapies. The second limitation is similar to a previous study with persistence, which indicated that the insufficient IOP-lowering efficacy of each drug depends on each clinician's judgement but not on the cut-off value. The third limitation is that prostaglandin-associated periorbital syndrome ${ }^{15}$ will increase after a long-term use of prostaglandin F2 $\alpha$ analogues; therefore, the persistence rate of the latanoprost group will decrease. However, similarly with omidenepag isopropyl, we have used only about 1 year of follow-up and unknown adverse effects may be observed. Further long-term observation is needed to determine whether omidenepag isopropyl can be used as the first-line treatment in patients with glaucoma.

In conclusion, we recommend that clinicians should note the characteristic adverse effects such as conjunctival hyperaemia and visual acuity disturbance during the early prescribed period. Overall, early persistence with omidenepag isopropyl was favourable, and the use of initial omidenepag isopropyl monotherapy is not far behind that of initial latanoprost monotherapy. Further long-term follow-up is also needed to determine new and different adverse effects.

Contributors SN: data collection, study design, data analysis and interpretation, manuscript writing, tables/figures creation. AK: study design, data collection, manuscript review and editing. YF: data collection and manuscript review. SW: data collection and manuscript review. YN: data collection and manuscript review. MA: study design, manuscript review and editing.

Funding The authors have not declared a specific grant for this research from any funding agency in the public, commercial or not-for-profit sectors.

Competing interests None declared.

Patient and public involvement Patients and/or the public were not involved in the design, or conduct, or reporting, or dissemination plans of this research.

Patient consent for publication Not required.

Ethics approval This retrospective, two-institution clinical study was approved by the Institutional Review Boards (IRB) of Saneikai Tsukazaki Hospital (IRB No: 191073), Japan and Kanamori Eye Clinic (IRB No: K2020-1), Japan, and was conducted in accordance with the Declaration of Helsinki.

Provenance and peer review Not commissioned; externally peer reviewed.

Data availability statement Data are available upon reasonable request. All data relevant to the study are accessed to Shunsuke Nakakura (shunsukenakakura@ yahoo.co.jp). No additional data are available.

Open access This is an open access article distributed in accordance with the Creative Commons Attribution Non Commercial (CC BY-NC 4.0) license, which permits others to distribute, remix, adapt, build upon this work non-commercially, and license their derivative works on different terms, provided the original work is properly cited, appropriate credit is given, any changes made indicated, and the use is non-commercial. See: http://creativecommons.org/licenses/by-nc/4.0/.

ORCID iD

Shunsuke Nakakura http://orcid.org/0000-0002-1094-1862

\section{REFERENCES}

1 Friedman DS, Wilson MR, Liebmann JM, et al. An evidence-based assessment of risk factors for the progression of ocular hypertension and glaucoma. Am J Ophthalmol 2004;138:19-31.

2 Moroi SE, Reed DM, Sanders DS, et al. Precision medicine to prevent glaucoma-related blindness. Curr Opin Ophthalmol 2019;30:187-98.

3 Jonas JB, Aung T, Bourne RR, et al. Glaucoma. Lancet 2017;390:2183-93.

4 Heijl A. Glaucoma treatment: by the highest level of evidence. Lancet 2015;385:1264-6.

5 Garway-Heath DF, Crabb DP, Bunce C, et al. Latanoprost for openangle glaucoma (UKGTS): a randomised, multicentre, placebocontrolled trial. Lancet 2015;385:1295-304.

6 Reardon G, Kotak S, Schwartz GF. Objective assessment of compliance and persistence among patients treated for glaucoma and ocular hypertension: a systematic review. Patient Prefer Adherence 2011;5:441-63.

7 Reardon G, Schwartz GF, Kotak S. Persistence on prostaglandin ocular hypotensive therapy: an assessment using medication possession and days covered on therapy. BMC Ophthalmol 2010;10:5.

8 Reardon G, Schwartz GF, Mozaffari E. Patient persistency with topical ocular hypotensive therapy in a managed care population. Am J Ophthalmol 2004;137:S3-12.

9 Reardon G, Schwartz GF, Mozaffari E. Patient persistency with ocular prostaglandin therapy: a population-based, retrospective study. Clin Ther 2003;25:1172-85.

10 Rait JL, Adena MA. Persistency rates for prostaglandin and other hypotensive eyedrops: population-based study using pharmacy claims data. Clin Exp Ophthalmol 2007;35:602-11.

11 Rahman MQ, Abeysinghe SS, Kelly S, et al. Persistence of glaucoma medical therapy in the Glasgow glaucoma database. $\mathrm{Br} J$ Ophthalmol 2011;95:966-70.

12 Duggan S. Omidenepag isopropyl ophthalmic solution $0.002 \%$ : first global approval. Drugs 2018;78:1925-9.

13 Aihara M, Lu F, Kawata $\mathrm{H}$, et al. Phase 2, randomized, dose-finding studies of omidenepag isopropyl, a selective EP2 agonist, in patients with primary open-angle glaucoma or ocular hypertension. $J$ Glaucoma 2019;28:375-85.

$14 \mathrm{FH} \mathrm{L}$, Aihara M, Kawata H. A phase 3 trial comparing omidenepag isopropyl $0.002 \%$ with latanoprost $0.005 \%$ in primary open-angle glaucoma and ocular hypertension: the AYAME study. Invest Ophthalmol Vis Sci 2018;59:1235.

15 Sarnoff DS, Gotkin RH. Bimatoprost-induced chemical blepharoplasty. J Drugs Dermatol 2015;14:472-7.

16 Nakakura S, Terao E, Fujisawa Y, et al. Changes in prostaglandinassociated periorbital syndrome after switch from conventional prostaglandin F2 $\alpha$ treatment to omidenepag isopropyl in 11 consecutive patients. J Glaucoma 2020;29:326-8.

17 Aihara M, FH L, Kawata H. Six-Month efficacy and safety outcomes of a novel selective EP2 agonist omidenepag isopropyl: the RENGE study (phase 3). Invest Ophthalmol Vis Sci 2018;59:1229.

18 Schwartz GF, Reardon G, Mozaffari E. Persistency with latanoprost or timolol in primary open-angle glaucoma suspects. Am J Ophthalmol 2004;137:S13-16.

19 Reardon G, Schwartz GF, Mozaffari E. Patient persistency with pharmacotherapy in the management of glaucoma. Eur J Ophthalmol 2003;13:44-52.

20 Dasgupta S, Oates V, Bookhart BK, et al. Population-based persistency rates for topical glaucoma medications measured with pharmacy claims data. Am J Manag Care 2002;8:S255-61.

21 Spooner JJ, Bullano MF, Ikeda LI, et al. Rates of discontinuation and change of glaucoma therapy in a managed care setting. Am J Manag Care 2002;8:S262-70.

22 Quek DTL, Ong G-T, Perera SA, et al. Persistence of patients receiving topical glaucoma monotherapy in an Asian population. Arch Ophthalmol 2011;129:643-8.

23 Juzych MS, Randhawa S, Shukairy A, et al. Functional health literacy in patients with glaucoma in urban settings. Arch Ophthalmol 2008;126:718-24.

24 Zhu Z, Jiang Y, Wang W, et al. Real-world assessment of topical glaucoma medication persistence rates based on national pharmaceutical claim data in a defined population. Clin Exp Ophthalmol 2019;47:881-91.

25 Kosoko O, Quigley HA, Vitale S, et al. Risk factors for noncompliance with glaucoma follow-up visits in a residents' eye clinic. Ophthalmology 1998;105:2105-11.

26 Medical personnel confirmation. Available: https://www.santen.co.jp/ medical-channel/di/safety/DI050_safety_eybelis.pdf [Accessed 9 Mar 2020]. 